\title{
THE PATHOLOGICAL AND CLINICAL ASPECTS OF DEAF-MUTISM.*
}

By J. S. FRASER, M.B, F.R.C.S.Ed., Surgeon, Ear and Throat Department, Royal Infirmary, Edinburgh.

IN the issue of this Journal for January 1921, Kerr Love, in his article on Deaf-mutism, says, "The thing most wanted from the pathologist at present is a series of post-mortem examinations of undoubtedly deaf-born children." Although the writer can only claim to add two records to the list of microscopic examinations of the ears of deaf-mutes, and though only one of these was "congenital," the present would appear to be a suitable occasion on which to place before British otologists an account of the work which has been done on this subject. In spite of careful investigation it must be admitted that as yet the matter remains unsettled. The majority of observers have laid stress on the importance of changes in the ear itself, especially in the labyrinth. A minority have attributed the deafness to lesions in the brain. Reliable accounts, however, of changes in the hearing tracts and centres are almost nonexistent, so that much work has still to be done before we can speak with any degree of confidence regarding the pathology of "central " deafness.

It is difficult to be exact with regard to the details of the various recorded cases. The writer finds in the literature that the same case is reported in several places. He cannot, therefore, lay claim to complete accuracy of description and can only plead that he has done his best to disentangle a very difficult subject.

There are three lines of research which undoubtedly throw considerable light on the question of congenital or "developmental" deaf-mutism-study of the comparative anatomy of the labyrinth, of the development of the inner ear, and of congenital deafness in animals. To go fully into these subjects is impossible in the present paper. They must therefore be left over for future consideration.

* The histological work in connection with this paper was carried out in the Laboratory of the Royal College of Physicians, Edinburgh. 


\section{J. S. Fraser}

Before reviewing the literature of congenital deaf-mutism, the writer desires to record the following case :-

K. M'D., male, aged I 3 years, was admitted to a Deaf and Dumb Institution at the age of 7 years, but had to be removed on account of frequent nocturnal enuresis. On re-admission after three years the incontinence was less troublesome. His parents stated that he had been born totally deaf, but his teacher in the oral class regarded him as having slight remains of hearing. The patient, however, could not repeat vowels spoken in the ordinary voice. As far as could be ascertained there were no other deaf members in the family. For several years the boy had suffered from foul-smelling otorrhœa (left). Two days before admission to the Royal Infirmary the patient complained of pain, and next day the school doctor noted mastoid tenderness. There were no rigors or vomiting.

Examination (18/9/10).-Temperature 102.5, pulse 88, respirations 20. Right drum-head indrawn; left meatus contained foul-smelling discharge. After syringing, granulations were seen to project from the posterior wall of the bony meatus at its inner end.

Functional Examination: Cochlear Apparatus. - Conversation voice not heard by either ear. The patient, however, nodded his head when the watch was applied to the mastoid process and auricle on each side, as if he heard something. C.32 and C.64 not heard by air conduction by either ear. C. 28 apparently heard by right ear but not by left. C. 256 was heard by both ears, and the tone of the fork correctly imitated by the boy. C.512 and C.1024 were also heard by both ears. C.2048 was not appreciated by either ear. Vestibular Apparatus. - No spontaneous nystagmus. Rotation tests not applied. Cold syringing of the right ear for ninety seconds produced distinct rotatory and lateral nystagmus to the left. Similar syringing of the left (discharging) ear produced slight nystagmus to the right in two minutes.

The case has already been recorded as a fatal intracranial complication of chronic middle-ear suppuration: death from purulent meningitis. (Journal of Laryngology, Otology, and Rhinology, vol. xxvii., 1912, p. 197, Case 98.) The post-mortem took place twelve hours after death.

Microscopical Examination of Left (Operated) Ear. Horizontal Sections from above downwards.

Tympanic Cavity.-There is marked inflammatory change in the mucosa of the attic and great swelling of the submucosa, with small cell infiltration. Cholesteatoma and pus are present in the antrum.

There is erosion of bone on the inner wall of the antrum and on the prominence of the lateral canal. The crura of the stapes 


\section{Pathological Aspects of Deaf-Mutism}

are present, and the footplate is healthy, but the mucosa of the oval window niche is much swollen. The round window membrane is normal (Fig. 9).

The bony labyrinth capsule is normal except for the erosion mentioned above.

Vestibule.-The neuro-epithelium of the utricle is healthy, but the otolith membrane is separated (artefact), Fig. 2. The sacculus is collapsed (Fig. 8). The epithelium of the saccule appears to be well formed in parts. Colloid bodies are seen in the saccule. The duct from the utricle to the endolymphatic duct is wide, but that from the saccule is narrow. The ductus endolymphaticus is rather wider than normal, as it passes through the bone (Fig. 8). The vestibular nerve stains well by the Kulschitzky method.

Cochlea. - There is a considerable quantity of curdled lymph in the scala tympani in the inner aspect of the round window membrane, but the endolymph spaces are fairly free. The opening of the aqueduct of the cochlea appears slightly narrower than normal.

Cochlear Canal.-Reissner's membrane for the most part passes vertically upward, so that the cochlear canal is dilated (Figs. 3, 4, 5, and 6); Corti's organ is badly formed (Figs. 4, 5, and 6); nowhere is the normal acoustic papilla visible. It is best developed in the apical portion. The pillar cells, though deformed, can be made out in parts.

Memurana Tectoria.-The position of the membrana tectoria is nowhere normal. It is enclosed in epithelium. In the basal coil it is tucked into the inner spiral sulcus (Fig. 4); higher up it is elevated; in the upper part of the basal coil it is attached to the stria vascularis (Figs. 3 and 5 ); in the middle coil it is turned inwards towards the modiolus and helicotrema (Figs. 3 and 6); the spiral ligament shows clear areas-so-called "dropsical degeneration." The stria vascularis does not present the normal appearance of a regular row of epithelial cells: at the apex of the cochlea it is almost absent (Fig. 3); the cochlear nerve itself is well formed, and the ganglion cells are present in apparently normal number: the cells appear somewhat shrunken, but have a well-marked nucleus.

Canals. - The cristæ of all the canals show slight desquamation of the epithelium and separation of the cupula-possibly associated with the high temperature before death (Fig. I). As is commonly seen, there is irregular formation of the bony walls of the canals (Fig. 2). The crus commune is normal.

Internal Meatus.-There is meningitis within the arachnoid sheath of the nerves in the internal meatus (Fig. 7). The vestibular ganglion cells appear slightly shrunken (artefact?), but they are present in normal number. 


\section{J. S. Fraser}

Saccus endolymphaticus.-There is some hæmorrhage in the bony hollow which contains the saccus endolymphaticus. The bone here is roughened as if the extradural abscess had extended to this region.

\section{Microscopical Examination of Right (non-operated) Ear.}

The tympanic cavity, ossicles and muscles are healthy, except for slight thickening of the mucosa and small cell exudation in the niche of the round window (Fig. 20).

Labyrinth capsule normal.

Vestibule. - The sacculus is collapsed (Fig. r9). The ductus reuniens is obliterated, and cannot be traced between the collapsed sacculus on the one hand and the intra-vestibular part of the cochlea on the other. The utriculus is normal (Fig. 20). The ductus endolymphaticus is much shorter than usual.

Cochlea.-The cochlear opening of the perilymphatic aqueduct is healthy (Fig. 19), but towards the cranial end the duct contains a few leucocytes. These are also seen in the scala tympani in the upper surface of the round window membrane. The cochlear duct is narrow and collapsed (Figs. Io, I I, I5, and I6). Reissner's membrane is bent downwards, and is adherent to the overgrown stria vascularis for at least half its extent. In the apical coil the scala media is quite filled up, and is adherent to the bony partition between the apical and middle coils (Fig. ro). Corti's organ is for the most part an irregular heap of cells. The membrana tectoria is adherent to Corti's organ, and also to the stria vascularis. In places it is tucked into the internal spiral sulcus (Figs. 12 and 13 ). The spiral ligament shows areas of degeneration (Fig. 13). The spiral ganglion cells appear normal in number (Fig. I 7), and the hollow space of the bony spiral lamina is well filled with nerve fibres (Figs. 14 and 15). The cochlear nerve in the modiolus is quite normal.

Canals are healthy.

Internal Meatus. - There are many pus cells and some blood in the fundus of the internal meatus between the arachnoid and dura mater (basal meningitis) (Fig. I8). The cochlear nerve in the internal meatus shows quite the normal thickness, but there is some meningitic infiltration round and between the nerve bundles (Fig. II). The vestibular ganglion cells are not diminished.

The saccus endolymphaticus is healthy.

Remarks. - The case is one of "congenital or developmental" deafness belonging to the Scheibe type, with slight remains of hearing and a normal or almost normal vestibular reaction. It is of interest that on the right side the cochlear canal is 


\section{Pathological Aspects of Deaf-Mutism}

collapsed, especially at the apex, while on the left side it is dilated. This condition, however, has been noted by previous observers.

\section{Classification of DeAF-mutism.}

Cases of deaf-mutism are usually divided into (I.) Congenital, and (II.) Acquired. At first sight this classification appears simple and convenient, but it is not scientifically accurate. Congenital deafness has usually been held to include not only "developmental" cases due to faults of the germ plasm, but also those due to such inflammatory conditions as intra-uterine meningitis. In other words, "congenital " has been regarded as synonymous with "before birth." Cases due to congenital syphilis are difficult to classify; they do not, as a rule, become deaf till childhood is well advanced, or even later. On the other hand cases in which there is a more or less gradual atrophy of Corti's organ and of the eighth nerve, as described by Politzer, are undoubtedly due to inherited weakness, though the clinical condition may only manifest itself some time after birth. It therefore appears to be more scientific to divide cases of deafmutism into those due to an error in development and those due to inflammatory conditions.

Unfortunately the boundary line between (I.) Congenital (developmental) deaf-mutism, and (II.) Acquired (inflammatory) deaf-mutism can not always be sharply demarcated. We know from experience that cases which are difficult to diagnose clinically also present difficulties to the pathologist and microscopist. For example, the presence of connective tissue in the perilymph space is usually held to indicate a past inflammatory condition. Alexander, however, points out that connective tissue normally present in the perilymph space of the embryo may not disappear, as it should, but may persist into extra-uterine life.

Siebenmann subdivides (I.) Congenital cases into (I) those with aplasia of the whole labyrinth, and (2) those in which the neuro-epithelium of certain parts of the endolymphatic space is more or less degenerated. The latter group (2) is further subdivided into $(a)$ those in which the metaplasia is confined to the basilar membrane, and $(b)$ those with extensive metaplasia or absence of sensory epithelium, associated with dilatation or collapse of the pars inferior (Scheibe's type). (II.) In cases of acquired deaf-mutism Siebenmann distinguishes (I) 


\section{J. S. Fraser}

those of meningitic origin; (2) those of tympanic origin; and (3) those with primary changes in the labyrinth, i.e., cases due to mumps, trauma, acquired syphilis. Politzer classifies cases of acquired deaf-mutism on a clinical basis into those due to (I) epidemic meningitis, primary meningitis, and hydrocephalus ; (2) otitis media from infectious diseases; (3) syphilis; (4) mumps and primary infection of the labyrinth; (5) injuries of the labyrinth.

Denker on the whole agrees with Siebenmann's classification, but subdivides congenital cases into (I) those due to intrauterine inflammatory processes, including syphilitic cases; and (2) those due to maldevelopment of non-inflammatory origin. The latter group is further subdivided into $(a)$ hereditary cretinoid degeneration (endemic deaf-mutism), and (b) hereditary degenerative (sporadic) deaf-mutism.

Hammerschlag points out that it may be difficult or impossible to say whether a labyrinthine affection occurred during intra-uterine or during the first year of extra-uterine life. He therefore divides deaf-mutism into two groups:-(I.) Constitutional deaf-mutism, and (II.) Deaf-mutism due to local disease of the ear, e.g., trauma or inflammation. (I.) Constitutional deaf-mutism is only part of a general constitutional anomaly and may be congenital or acquired. It is subdivided into-(I) An endemic or cretinoid form due to the same poison responsible for endemic cretinism ; (2) sporadic or hereditary degenerative deaf-mutism. Constitutional affections, according to Hammerschlag, show three characteristics. Firstly, they are hereditary, either directly or indirectly; secondly, they occur more than once in the same generation; and thirdly, they are associated with other hereditary degenerative conditions. In constitutional deaf-mutism, for example, we find, if we go thoroughly into the matter, a family history of deafness, or at least of deficient hearing, in several members of the family, and, in addition, other stigmata of degeneration, such as albinism, retinitis pigmentosa, squint, etc. (II.) Deaf-mutism due to local disease of the organ of hearing is always acquired, whether in fœtal or post-fœtal life.

Urbantschitsch also divided deaf-mutism into-(I.) Congenital, and (I I.) Acquired. (I.) Congenital deaf-mutism includes (I) Cases of hereditary degenerative character due to a fault in the germinal layers. In some of these the disposition is latent and only becomes manifest when some other cause arises. In most 


\section{Pathological Aspects of Deaf-Mutism}

cases, however, the disposition is apparent from the beginning. (2) Endemic or cretinoid deafness. (II.) Acquired cases, according to Urbantschitsch, may be either (1) Intra-uterine (including cases resulting from congenital syphilis), or (2) Post-fotal.

Urbantschitsch's Classification of Deaf-mutism.

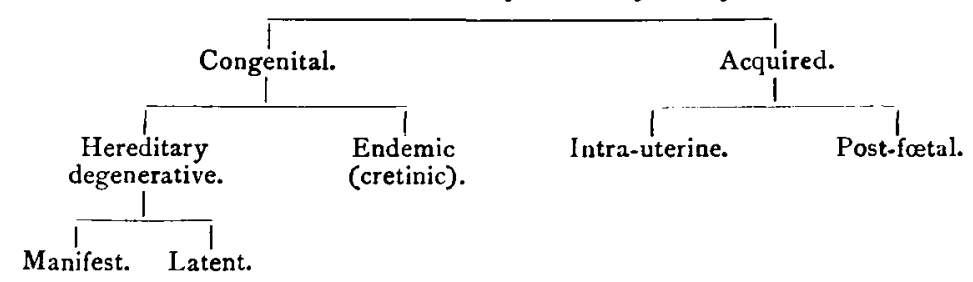

Goerke has put forward another classification into two groups-(I.) Embryonic, and (II.) Post-embryonic. In the embryonic category Goerke includes cases in which the ear is affected during its development, while all the remaining forms belong to the second group. Here again we meet with the difficulty that it may be almost impossible to say, even on microscopic examination, whether a given case is of embryonic or post-embryonic origin. Only cases of aplasia of the temporal bone can with certainty be regarded as embryonic, because recent investigations are said to show that malformation of a hypoplastic kind may be caused by intra-uterine inflammation. Even the labyrinth anomalies of the anencephalic foetus may be of an inflammatory nature because the brain change itself may be due to inflammation.

Alexander states that in most cases of congenital deaf-mutism there was originally a defective embryonic rudiment of the nerve ganglia and of Corti's organ (Scheibe's type). In a smaller number of cases, on the other hand, the embryonic rudiments were normal, but, owing to faulty development of the tympanic cavity and capsule of the labyrinth, there resulted secondary atrophy of the ganglia and degeneration of Corti's organ (Siebenmann's and Mondini's types).

Brouwer classifies deaf-mutes into (I.) those with inflammatory changes in the labyrinth-acquired cases; (II.) those. with destruction of the temporal lobes; (III.) those with changes in the inner ear but no sign of inflammation. Brouwer thinks that the degeneration of the peripheral hearing organ in this third group is the result of disease of the medulla oblongata, possibly resulting from internal hydrocephalus. 


\section{J. S. Fraser}

After considering carefully the various views as to the classification of deaf-mutism put forward by different observers, the writer has come to the conclusion that it is best to adopt Hammerschlag's view and divide cases of deaf-mutism into (I.) those apparently due to errors in development; and (II.) those due to inflammatory conditions or traumatism. The writer does not believe that sporadic congenital deaf-mutism is due to intra-uterine meningitis, firstly, because the membranous labyrinth is developed from the epiblast and only later becomes connected to the central nervous system by means of the acoustic ganglia and eighth nerve; secondly, because it is difficult or impossible to think of foetal meningitis affecting only the saccule and cochlea and leaving intact the remaining parts of the membranous labyrinth, especially as in many cases the cochlear nerve and ganglion appear to be normally developed; and, thirdly, because the changes observed in congenital deafness differ so markedly from those produced in the inner ear in cases of meningitic labyrinthitis in postfotal life.

With regard to the relative frequency of congenital as compared with acquired cases of deaf-mutism, the original view was that the former greatly out-numbered the latter. More recently, in the light of our increasing knowledge of labyrinthitis, the original view was reversed and the conclusion reached that, at any rate in countries in which endemic cretinism and deafmutism are rare, the acquired cases out-numbered the congenital. We must remember, however, the great difficulty of making a diagnosis between congenital and acquired cases in the living subject, when we have only the history-often inaccurate-and the clinical examination of the case to guide us. Even microscopic examination of the labyrinth in some cases of deaf-mutism does not always provide us with an absolutely clear picture of the cause of deafness, but, in the great majority of cases, there can be little doubt in classifying a given case as either "congenital or developmental" on the one hand, as opposed to "acquired or inflammatory" on the other. If, then, we take it that the labyrinths of deaf-mutes who have come to autopsy, have been impartially examined, we must conclude that the congenital cases out-numbered the acquired ones. This conclusion is confirmed by an analysis of the clinical examinations of a series of cases of deaf-mutism carried out by the writer to be published in the second part of this paper. 


\title{
Pathological Aspects of Deaf-Mutism
}

\author{
I.-CONGENITAL OR DEVELOPMENTAL DEAF-MUTISM \\ (Constitutional Deaf-MUTiSM OF HaMMERSChLaG).
}

\section{(A.) Endemic or Cretinic Deafness. (Siebenmann's Type.)}

Clinical Aspect.-Patients may be mentally feeble and, in later life, demented, or they may be congenital idiots. A few are mentally bright. Most of the cases were complete cretins. Goitre may be present in the patients and other members of the family. The majority of the patients are deaf from birth, but one case of Mannasse's, though dumb, only became deaf at i 4 years. Some of Nager's cases showed sound-conduction deafness and had remains of hearing about the middle of the scale. Siebenmann states that many endemic deaf-mutes can perceive tones over the whole eleven octaves though the hearing is greatly diminished. Habermann has examined clinically I 2 cases of cretinism and always found diminution of hearing. Stein states that 25 per cent. of cretins have normal hearing, 45 per cent. slight deafness, 25 per cent. severe deafness, and 5 per cent. absolute deafness. As a rule the disturbance of hearing is parallel with that of the bodily and intellectual development, but it may be the only symptom of cretinoid degeneration. Mannasse believes that a degenerative family disease is present, including struma, cretinism, and congenital deafness. Nager mentions the broad-based, waddling gait of his patients. He attributes this to changes in the brain.

\section{Anatomical Changes :-}

(I) External Ear.-In one of Nager's cases the lobule of the left ear was slit and there was also a pre-auricular cartilage.

(2) Middle Ear.-The changes here are important and have been described by Siebenmann, Politzer, Habermann, Nager, Mannasse, Alexander, Moos and Steinbrügge, Mayer, Oppikofer, Denker, Schlittler and Brock. Alexander mentions myxomatous thickening of the submucous tissues of the middle ear. In the great majority, if not in all cases, there was filling up of the window niches by connective tissue and fat cells. Nager believes that this is due to the transformation of myxomatous tissue. In many, the long process of the incus and the head or posterior limb of the stapes were adherent to the facial canal by connective tissue or bone, and in some the incus was ankylosed by bone to the aditus or to the tegmen tympani. Several writers mention thickening of the footplate of the stapes or bony ankylosis to vol. XXXVII. No. I. 


\section{J. S. Fraser}

the margin of the oval window. The crura may be joined together. Siebenmann mentions absence of the stapedius tendon. The sinus tympani may be absent. Exostoses are frequently found on the promontory, and there may be osteoporosis of the whole promontory wall. Alexander and Nager have noted areas of otosclerosis in cases of cretinic deafness. General bony narrowing of the tympanic cavity has been described-indeed the tympanum may be obliterated by new-formed, spongy bone. Even the antrum may be filled up and the mastoid abnormally small. Habermann and Nager found inflammatory changes in the middle ear in several cases. These may have been accidental, but, on the other hand, it is possible that the middle ear changes characteristic of cretinic deafness may be the results of otitis media.

(3) The Labyrinth Capsule is often thick and sclerotic. (In this connection Nager points out the embryological relationship between the stapes footplate and the labyrinth capsule, but admits that it is the outer or periosteal layer of the capsule that is mainly affected and the tympanic surface of the footplate that is thickened. Nager agrees that these changes may be associated with otitis media.) Endostoses have been reported growing from the labyrinth capsule into the hollow spaces of the cochlea, vestibule, and canals. The affection of the labyrinth capsule may produce deformity of the cochlear scalæ, which are angular on section rather than oval or circular. Siebenmann and Nager mention that the bony walls between the various coils of the cochlea may be very thin and in parts only membranous.

(4) Inner Ear.-Habermann, Schlittler, and many others have found the inner ear normal; indeed, few writers have reported any gross abnormality, though some mention such conditions as slight swelling of the membrana tectoria and atrophy of the spiral ligament. In one of Nager's cases the cochlear duct was dilated in the lower and collapsed in the upper part. Mannasse states that in his case Corti's organ was replaced by cubical epithelium, while the cristæ and maculæ were atrophic. He notes, however, that the changes seen are really those of chronic progressive labyrinthine deafness. In Siebenmann's case the acoustic papilla was very low and Reissner's membrane depressed. In a human cretin Alexander found marked degenerative changes in Corti's organ but only slight changes in the nerve and ganglia, while in a deaf cretinic dog he noted partial obliteration of the cochlear canal. Corti's organ was absent in places, and, through- 


\section{Pathological Aspects of Deaf-Mutism}

out, the hair and pillar cells were not to be seen. Further, Alexander noted a poor vascular supply to the labyrinth in one case, similar to that observed in albinotic congenitally deaf animals. Some observers have noted that the spiral ganglion cells were reduced in number in the basal coil, and that there was an increase of connective tissue around them. The fine nerve fibres in the modiolus and bony spiral lamina may be very thin. In one case Nager found a small tumour (neurofibroma) on a branch of the cochlear nerve in the modiolus. In Siebenmann's case the cochlear nerve itself was very thin.

(5) Brain.-In one of Nager's cases the dura was thickened and adherent to the skull. Brain changes were also present. Alexander, on the other hand, found no change in the acoustic nuclei, in the central paths, or in the temporo-sphenoidal lobe.

Summary.-On the whole, then, we may say that in endemic or cretinic deafness there are marked changes in the middle ear and labyrinth capsule, including the window niches, whereas the inner ear in the majority of cases shows practically normal conditions. This is in marked contrast to the conditions found in sporadic congenital deafness, in which the membranous labyrinth and eighth nerve are at fault. Nager states that tuning-fork tests show that many cretinic deaf-mutes are really only "hard of hearing." This degree of deafness, however, in conjunction with the feeble mental development results in deaf-mutism.

\section{Views as to Pathology of Endemic Deaf-mutism.}

A Developmental Anomaly-Mannasse, Mayer, Hammerschlag, Stein, and Goerke believe that the changes are developmental and are caused by a congenital constitutional anomaly. Siebenmann believes that they occur between the fourth and sixth months of fotal life. Goerke calls attention to the presence in these cases of other similar anomalies, secondly, to the absence of any sharp line of demarcation between normal and pathological bone, and thirdly, to the persistence of embryonic tissue in various parts of the middle and inner ear. Mannasse thinks that the labyrinthine changes result from a slow atrophic degenerative process which may begin in intra-uterine life. Hardness of hearing is produced by changes in the middle ear, especially in the window niches, but complete deafness comes on when labyrinth atrophy occurs. Stein points out the 


\section{J. S. Fraser}

similarity of the changes observed in some cases of cretinic deafness to those seen in Scheibe's type of sporadic congenital deafness. Stein holds that the changes in the inner ear and eighth nerve are developmental, but looks on the middle ear changes as post-embryonic and due to the failure of the normal resorption. On the whole, Stein groups endemic deaf-mutism along with sporadic congenital deaf-mutism (Hammerschlag's hereditary degenerative deafness), and includes them both under the heading of "constitutional" deafness.

Deafness due to Brain Changes.-Bircher, Kocher, Scholz, and Schlittler hold that the changes are in the brain. (Alexander, however, found the brain apparently free from disease.) Schlittler calls attention to the remarkable conjunction in these cases of deaf-mutism with a normal inner ear, but thinks that the changes in the sensory epithelium may be too delicate for observation by our present methods. Siebenmann and Nager take the view that in many cases the deafness is the result of changes in the brain due to intra-uterine meningitis. Nager believes that the tympanic changes are caused by faulty resorption of foetal connective tissue, and further suggests that the changes in the labyrinth capsule may be due to rickets. Denker holds that the deafness is due to disturbance of the central nervous system resulting from disorders of metabolism owing to loss of thyroid secretion, because in dogs whose thyroids had been removed there was no reaction to sound, and yet the middle and inner ears, along with the central paths, showed no degenerative or other changes.

Nager believes that in the later period of intra-uterine life the "goitre poison" influences the whole of foetal development, including the thyroid glands. This leads to disturbed ossification and dwarfism, as well as to the brain changes causing imbecility or idiocy. Siebenmann holds that the deafness cannot be explained by the absence of thyroid secretion, because in a case of total aplasia of the thyroid gland in a case of athyreosis with dwarfism, aged I 3 years, he found the inner ears normal. This shows that the thyroid gland is not necessary for the development of the membranous labyrinth during intrauterine life. Siebenmann and Nager believe that the causes of cretinism and cretinoid deafness are not want, in-breeding, and other social conditions, but rest on a geological basis. It has been said that in Europe mutism diminishes from the Alps towards the sea. 
The Pathological and Cunical aspects of Deaf.Mctism.-J. S. Fraser.

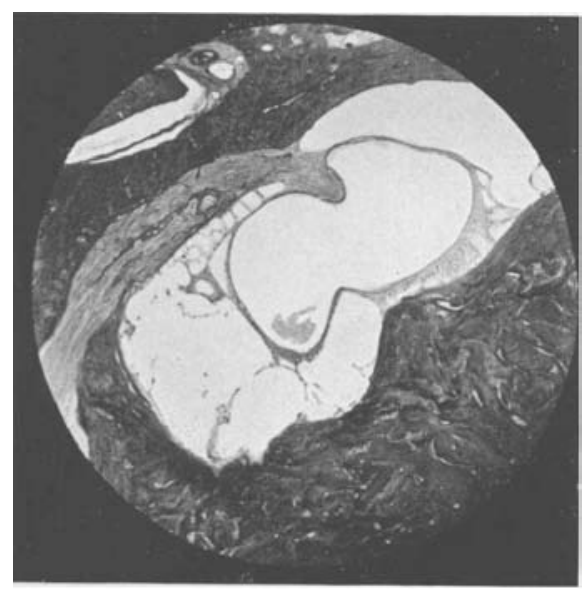

FIG. I.

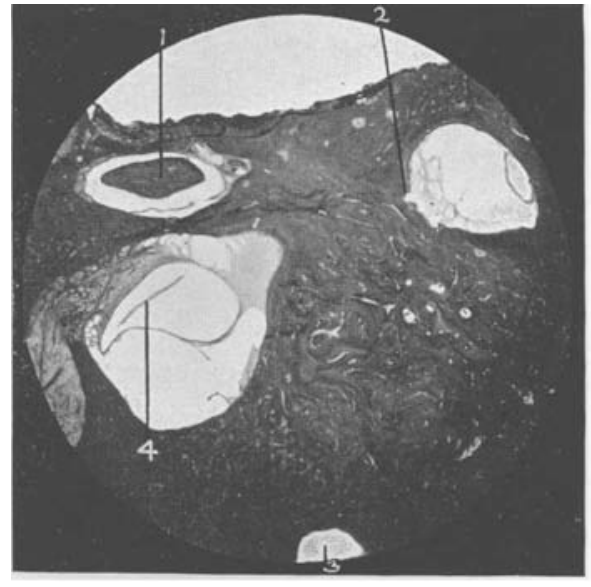

FIG. 2 .

FIG. I.-Case I. K. M'D., male, aged I3 years, Congenital Deaf-Mute. Section No. I65. Horizontal section through left ear. $\times$ I 3 diam. Shows normal condition of crista of lateral canal.

FIG. 2.-Case I. Horizontal section of left ear. No. 210. $\times 6$ diam. I. Facial nerve. 2. Irregularity of bony wall of lateral canal-a common appearance. 3. Smooth end of superior canal. 4. Separated otolith membrane of utricle (artefact?). The neuro-epithelium is normal.

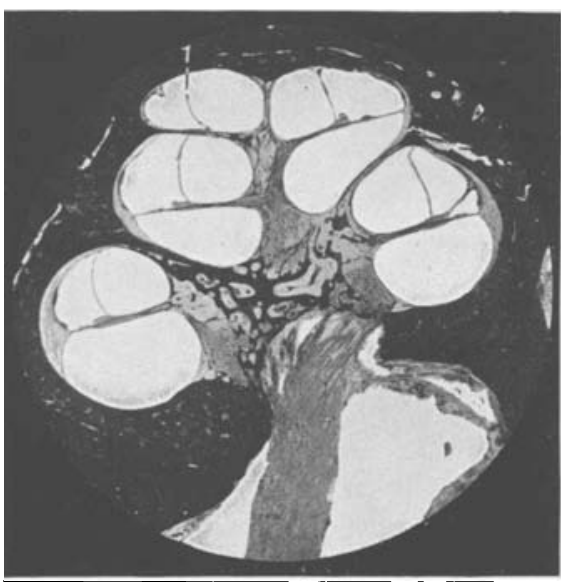

F IG. 3.

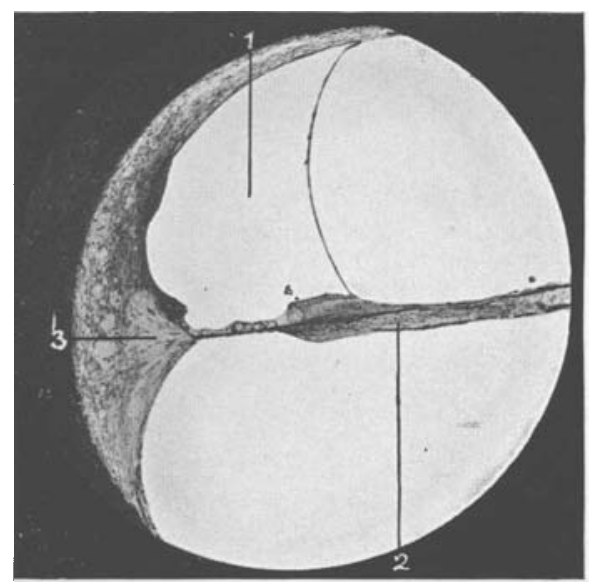

FIG. 4.

FIG. 3.-Case I. IJorizontal section through left ear. No. 250. x II diam. Axial section through cochlea. Shows dilatition of cochlear duct in all coils. The cochlear nerve and spiral ganglion appear normal. I. Reissner's membrane is ruptured at the apex of the cochlea (artefact?), and here the basilar membrane lies on the bony lamella which separates the upper part of the middle coil from the apical coil. The helicotrema is absent.

FrG. 4.-Case I. Horizontal section through lower part of left basal coil. No. $250 . \times 45$ diam. Note that the membrana tectoria is tucked into the internal spiral sulcus. Corti's organ is rudimentary, but the inner pillar cell can be made out. I. Dilated cochlear duct. 2. Nerve in bony spiral lamina, apparently normal. 3. Spiral ligament which shows the so-calied dropsical degeneration. 


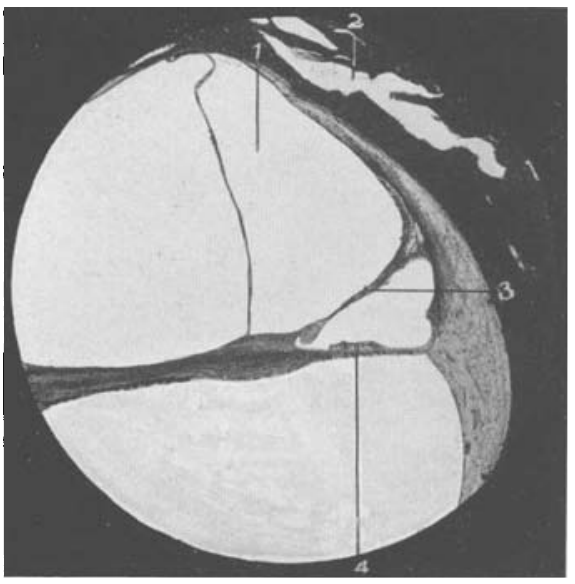

FIG. 5.

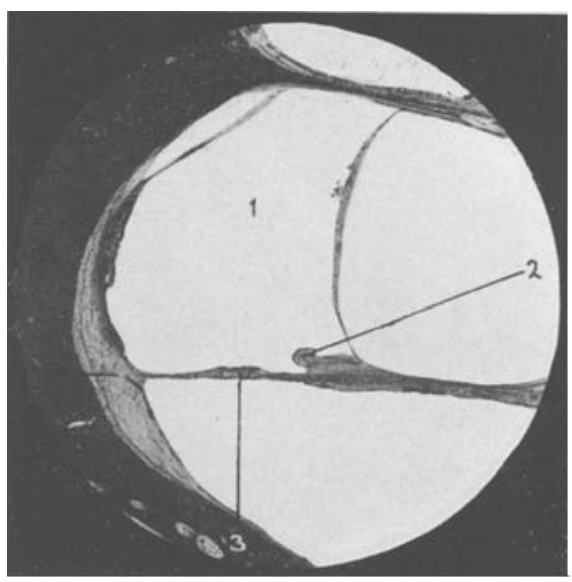

FIG. 6.

FJG. 5.-Case J. Horizontal section through upper part of left hasal coil. No. 250. $\times 45$ diam. I. Dilited cochlear duct. 2. Split in the bony cipsule (artefact). 3. Adhesion between membrana tectoria and stria vascularis. 4. Rudimentary Corti's organ.

FIG. 6.-Case I. Horizontal section through lower part of left middie coil. No. $250 . \times 45$ diam. I. Dilated cochlear duct. 2. Membrama tectoria lying on the apex of the limbus. 3. Rudimentary Corti's organ. 4. Spiral ligament showing dropsical degeneration. The stria vascularis appears to be well formed.

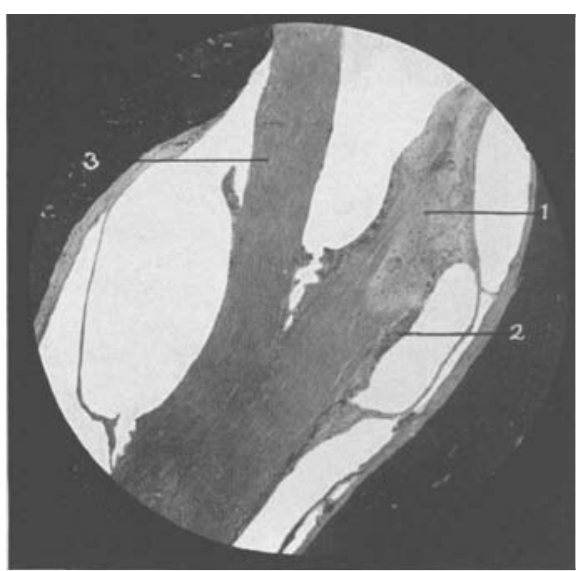

FiG. 7 .

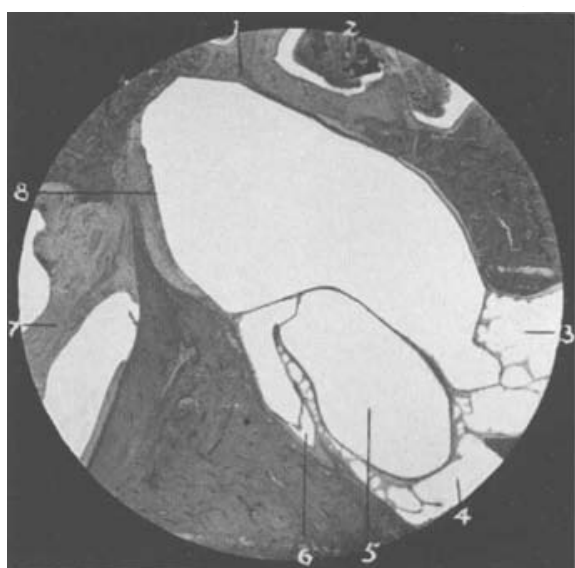

FIG. 8.

FIG. 7.-Case I. Horizontal section through cochlear and restibular nerves in left internal meatus. No. 250. X I I diam. I. Vestibular ganglion. 2. Meningitic infiltration. 3. Cochlear nerve which is well formed.

FIG. 8.-Case I. Horizontal section through left ear. No. 290. $\times 1$ I diam. I. Footplate of stapes. 2. Purulent exudate in hollow of stapes. 3. Opening of smooth end lateral canal into vestibule. 4. Crus commune. 5. Utricle. 6. Ductus perilymphaticus. 7. Nerve to saccule surrounded by meningitis. 8. Collapsed saccule. 


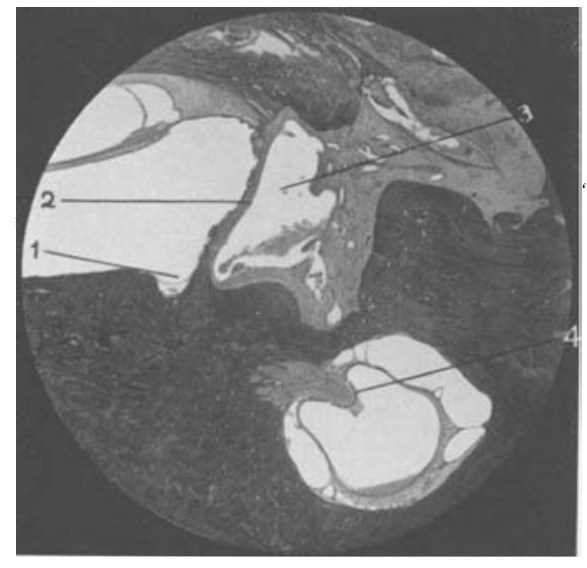

Fig. 9.

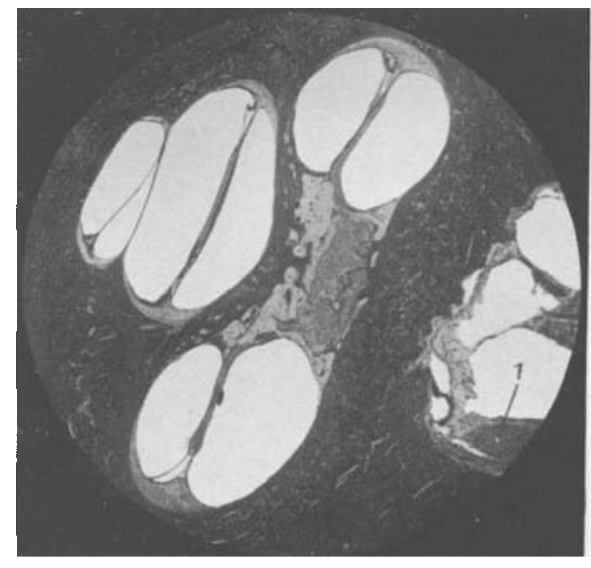

FIG. IO.

FIG. 9.-Case I. Iorizontal section through left ear. No. $386 . \quad \times$ I I diam. I. Cochleatr opening of perilymphatic aqueduct, containing a few pus cells. 2. Round window membrane with pus cells on it ujper or labyrinthine aspect. 3. Niche of round window. 4. Crista of posterior canal, normal.

FIG. Io.-Cace I. Vertical section through right ear. No. I. $\times$ Io diam. On this side the cochlear duct is collapsed in all coils. I. Meningitic infiltration in fundus of intemal anditory meatus. Note curious appeirance of membranous cochlea of apical coil. The membranons canal is collapsed and attiched to the bony partition between the apical and middle coils.

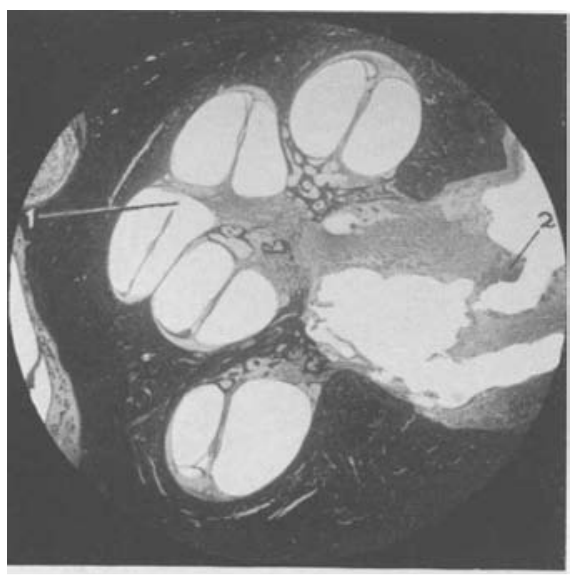

FIgr, II.

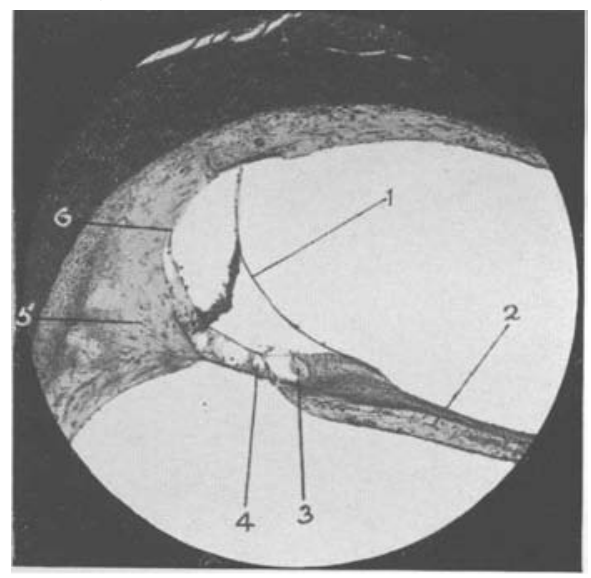

FIG. I 2.

FIG. I I.-Case I. Vertical section through right ear. No. 55. Axial section through cochlea. $\times 8$ diam. Cochlear nerve and ganglion are normal. I. Helicotrema. 2. Meningitic infiltration in internal meatus.

FIC. 12.-Case I. Vertical section through lower part of right basal coil. No. 55 . $\times$ so diam. I. Reissner's membrane depressed and attached to region of spiral prominence by band of connective tissue. 2. Nerve in bony spiral lamina, normal. 3. Membrana tectoria tucked into intemal spiral culcus. 4. Tunnel of Corti. The sensory cells and the other supporting cells are absent. 5. Dropsical degeneration and spiral ligament, 6. The stria rascularis is misplaced. 


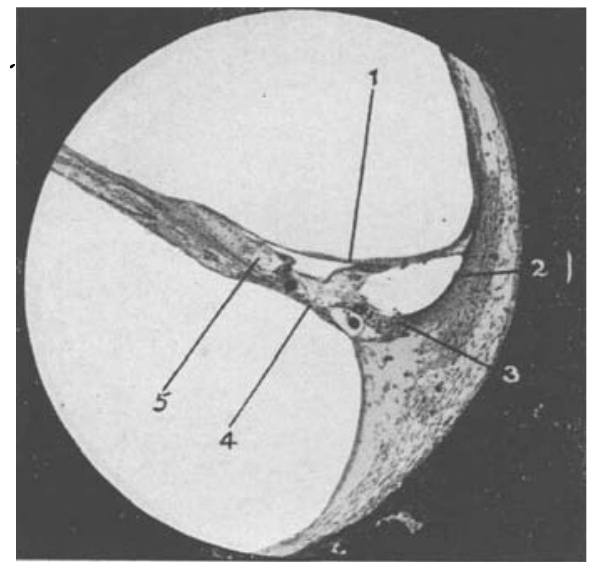

FIG. I3.

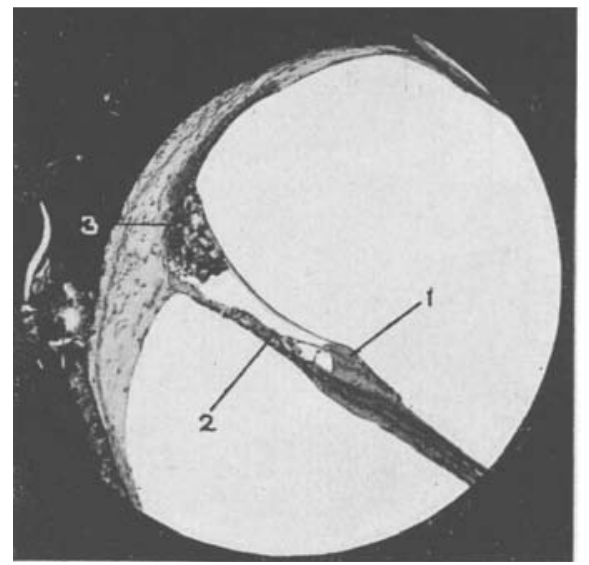

Fig. $1_{4}$.

FIG. I3.-Case I. Vertical section through upper part of right basal coil. No. 55. × 50 diam. I. Reissner's membrane depressed and attached to basilar membrane. 2. Position of stria rascularis, which is absent. 3. Position of spiral prominence. 4. Basilar membrane. 5. Membrana tectoria tucked into internal spiral sulcus. It will be seen that there is a complete malformation of the epithelium lining the cochlear canal, which is represented by at least four spaces in the section.

FIG. I+.-Case I. Verical section through lower part of right middle coil. No. 55. $\times 50$ diam. r. Membrana tectoria, which lies between the origin of Reisner's membrane and the limbus. 2. Rudimentary Corti's organ. 3. Great proliferation of stria vascularis, which occupies the outer third of the narrow cochlear canal.

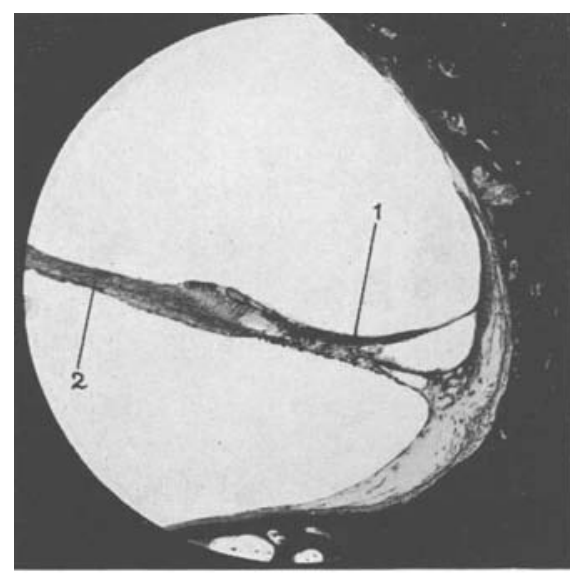

FIG. I5.

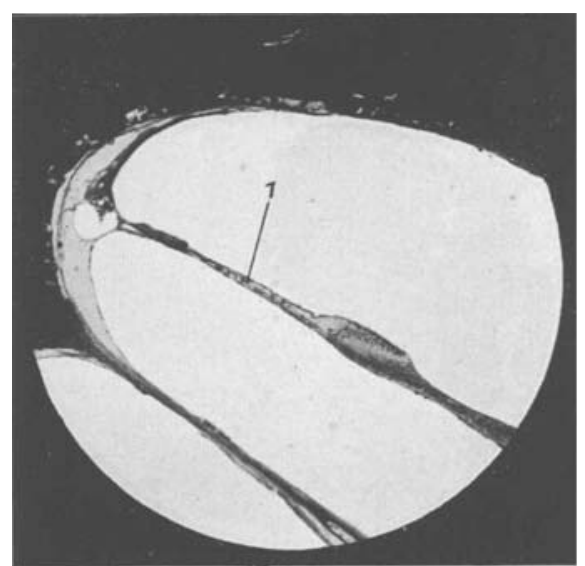

FIG. 16.

FIG. I5-Case I. Vertical section through upper part of right middle coil. No. 55. x 50 diam. I. Reissner's membrane adherent to basilar membrane. 2. The nerve in the bony spiral lamina is normal.

FIG. I6.-Case I. Tertical section through right ear. No. 55. $\times 50$ diam. I. Ipper blind end of cochlear duct, showing complete collapse. 


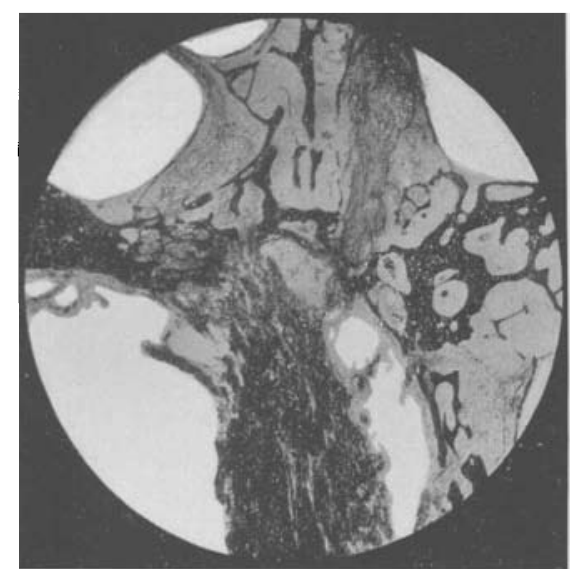

FIG. I7.

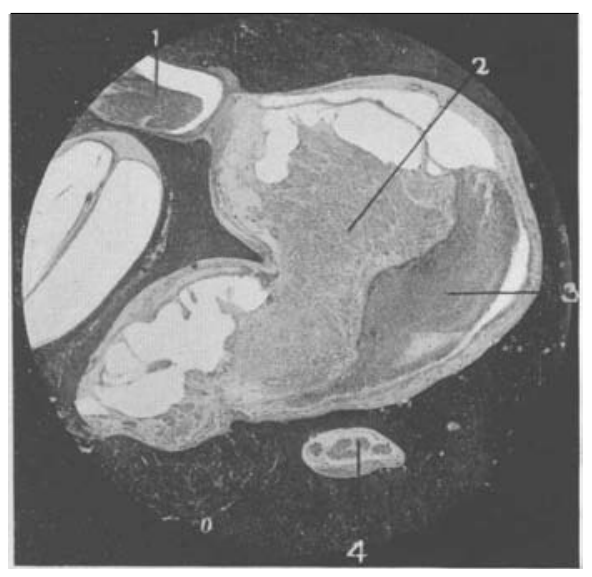

FIG. 18.

FIG. I7.-Case I. Vertical section through right ear. $\times 28$ diam. Section No 70 stained by Kulschit:k5-Pal method to show condition of cochlear nerve and ganglion cells. Note that these stain normally. Shows the internal meatus and part of the modiolus.

Fig. I8.-Case I. Vertical section of right ear. No. I50. $\times 9$ diam. Shows internal meatus with vestibular ganglion. I. Facial nerve. 2. Vestibular ganglion. 3. Mleningitic infiltration between dura and arachnoid. 4. Nerve to ampulla of posterior canal.

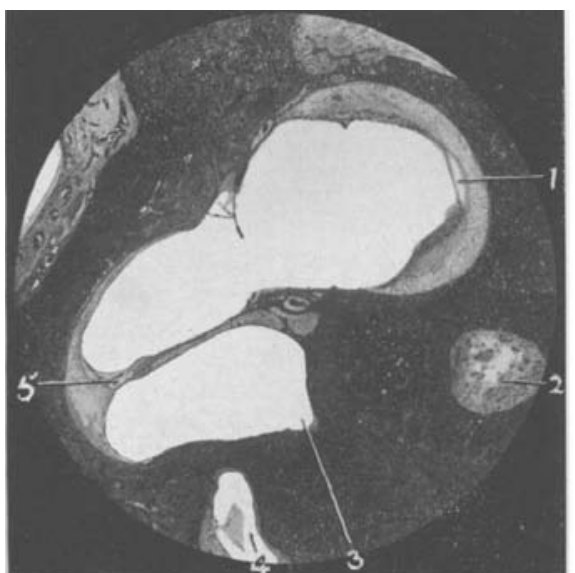

FIG. Ig.

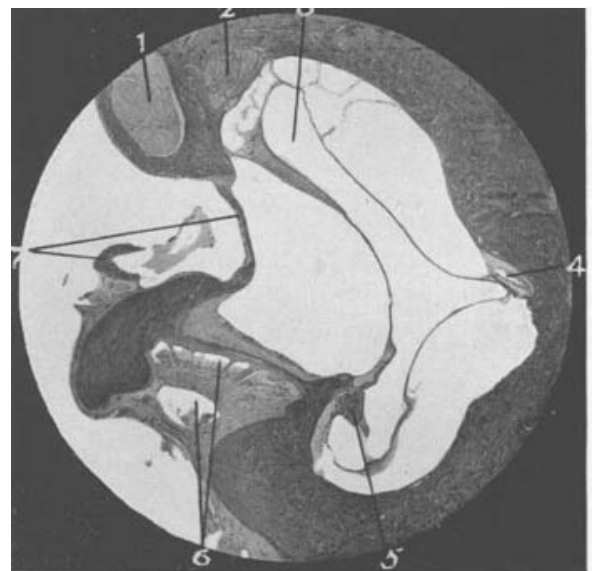

FIG. 20.

FIg. I9.-Cace I. Vertical section of right ear. No. 226. $x$ I 3 diam. I. Collapsed saccule. 2. Nerve to ampulla of posterior canal. 3. Opening of aqueduct of cochlea. 4 . Niche of round window. 5. Cochlear duct.

FIG. 20.-Case I. Vertical section through right ear. No. $3 I_{5} . \times 8$ diam. I. Facial nerve. 2. Vestibular nerve. 3. Itricle (neuro-epithelium normal). 4. Endolymphatic duct. 5. Crista of posterior canal, normil. 6. Niche of round window, and, above this, the blind restibular end of the cochlear duct. 7. Stapes. The heid is lightly attached to promontory. 


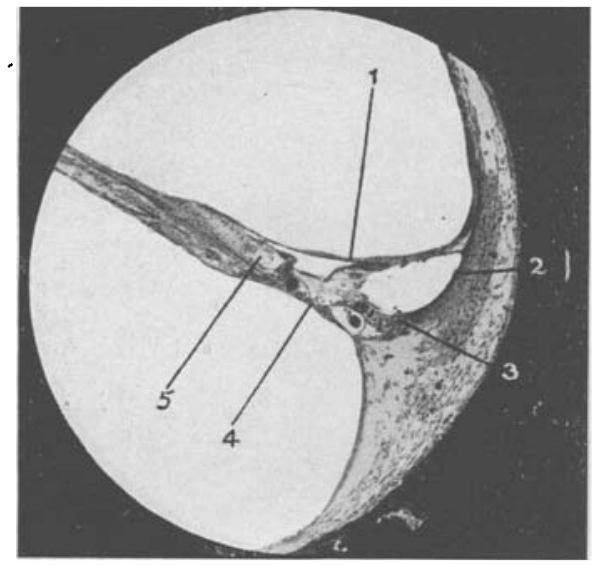

FIG. I3.

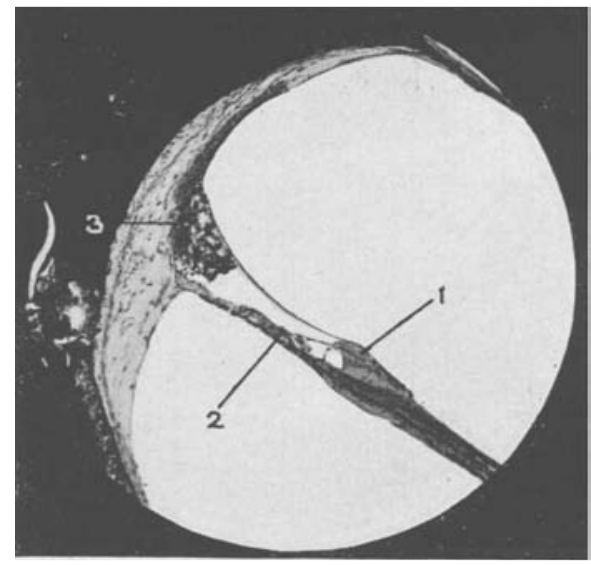

F16. I4.

FIG, I3.-Case I. Vertical section through upper part of right basal coil. No. $55 . \times 50$ diam. I. Reissner's membrane depressed and attached to basilar membrane. 2. Position of stria vascularis, which is absent. 3. Position of spiral prominence. 4. Basilar membrane. 5. Membrana tectoria tucked into internal spiral sulcus. It will be seen that there is a complete malformation of the epithelium lining the cochlear canal, which is represented by at least four spaces in the section.

FIG. If,-Cave I. Vertical section through lower part of right middle coil. No. 55. $\times 50$ diam. I. Membrana tectoria, which lies between the origin of Reiscner's membrane and the limbus. 2. Rudimentary Corti's organ. 3. Great proliferation of stria vascularis, which occupies the outer third of the narrow cochlear canal.

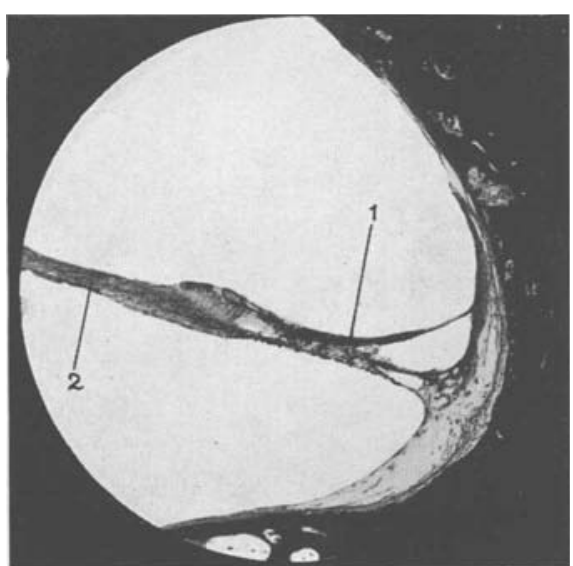

FIG. I5.

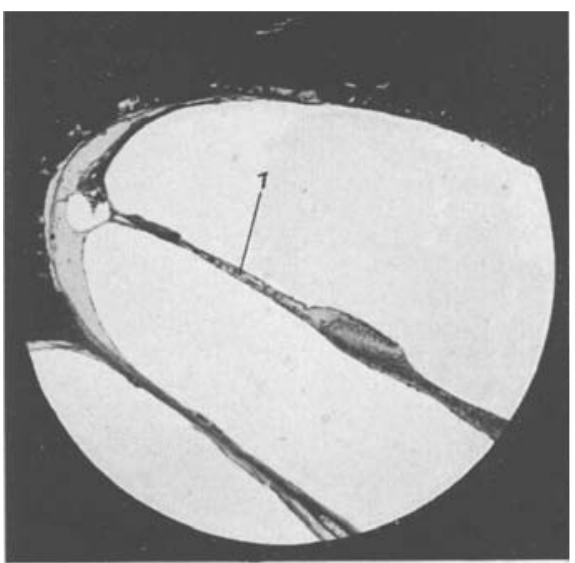

FIG. I6.

FIG. I5 -Case I. Vertical section through upper part of right middle coil. No. $55 . \times 50$ diam. I. Reissner's membrane adherent to basilar membrane. 2. The nerve in the bony spiral laminit is normal.

FIG. I6.-Case [. Vertical section through right ear. No. 55. $\times 50$ diam. I. Cpper blind end of cochlear duct, showing complete collapse. 


\section{Pathological Aspects of Deaf-Mutism}

(B) Sporadic Congenital Deafness.

(I) Aplasia of the Whole Labyrinth. (Michel's Type.)

Only one case of this kind has hitherto been recorded-that by Michel. In this there was a double defect of both labyrinths and eighth nerves, while the external meatus and tympanic membranes were normal. The tympanic cavity, however, was narrow, and there was only a hint of the mastoid antrum. Indeed the mastoid process is described as being absent. Siebenmann explains this condition by postulating absence of the otic vesicle in the first month of foetal life. Schwartze has examined the head of a new-born child with premature synostosis of the skull. The petrous pyramid was very thin and showed no trace of the semicircular canals or other parts of the labyrinth. The middle ear was well developed. The case strongly resembles Michel's. Siebenmann states that Virchow and Marfan-Armand-Delille have recorded cases of complete absence of the pyramid. The tympanic cavity, facial canal, labyrinth and nerves were also absent. Ogston has published the case of a child one year old, who suffered from congenital atresia of the external auditory meatus on one side. A macroscopic examination showed atrophy of the eighth nerve, hemiatrophy of the cerebrum and cerebellum, hypoplasia of the pyramid, and absence of the third, tenth, and eleventh nerves.

Siebenmann thinks that congenital atresia of the external meatus is not infrequently combined with malformation of the middle and inner ear. He has collected ten cases of bilateral congenital atresia and three of unilateral affection. Clinically some of the patients appeared to be quite deaf, but in others the labyrinth was not severely affected. Alexander states that, in most cases of congenital atresia, functional examination shows a normal condition of the labyrinth.

(2) Cases in which both the Bony and Membranous Labyrinths are affected. (Mondini's or Alexander's Type.)

Ibsen and Makeprang have recorded five cases of this type of congenital deaf-mutism. They, however, did not examine their specimens microscopically. There are transition forms between Mondini's type of deaf-mutism and that of Scheibe (to be described later).

Clinical Aspect.-Alexander's case was completely deaf. 


\section{J. S. Fraser}

Mayer's case was somewhat hard of hearing as a child, and suffered from tinnitus from the age of thirty years. The patient's wife, however, stated that he only became deaf five years before death, at the age of 75 . Hearing tests carried out by Mayer showed nerve deafness, more marked on the left side. Alt's patient was deaf from birth, and a sister was also deaf, while a younger brother was hard of hearing. Functional tests showed complete deafness for speech, but musical tones and noises were heard. Hearing remains have not been observed in other cases belonging to this type of deafness.

Middle Ear.-In Alexander's case the right middle ear was normal, but the drum-head was remarkably oval. In Alt's case the drum-heads were normal, and the middle ear practically healthy.

Bony Labyrinth.-In Mondini's case, the whole bony capsule of the cochlea was fiattened from base to apex. A more or less normal arrangement of the scalæ was only present at the lower part of the cochlea. In the upper part there was a wide common space, through the middle of which a thin ledge ran at right angles to the modiolus. The ledge was partly bony and partly cartilaginous. Alexander points out that a similar condition is seen at the second and third month of foetal life, and holds that in these cases normal development stops at this period. Alexander notes poor blood supply and pigmentation in his specimen. In Iwanow's case the scalæ of the middle coil communicated with one another as there was no dividing wall. The helicotrema was absent. In Schœnemann's case there was complete defect of the bony skeleton of the middle and apical coils. On the left side there was an osteoma growing from the remnant of the lamina. The bony partition between the middle and apical coils was absent in Mayer's case. As Alexander points out, this results in the formation of a scala communis.

Vestioular Apparatus.-Alt found the sacculus collapsed; the utricle showed no differentiation of sensory cells. The cristæ of canals were small. Alexander mentions atrophy of the maculæ of the utricle and saccule.

Aqueduct of Vestibule and Saccus Endolymphaticus.-In Mondini's and Schoenemann's cases the aqueduct of the vestibule was dilated and formed a gutter only closed by membrane posteriorly. (A similar condition has been noted by Gray in certain animals.) The saccus itself was very large and tensely filled. 


\section{Pathological Aspects of Deaf-Mutism}

Cochlear Duct and Corti's Organ.-Alt notes that in his case the cochlear canal was collapsed and the epithelium replaced by darkly pigmented or hyaline masses. In Mayer's case the scala media was dilated in all coils. Alexander, Iwanow, and Schœenemann also found atrophy and degeneration of the epithelium of the cochlear duct. Alexander noted that Corti's organ was absent in many places; in others it showed an embryonic form, i.e., it consisted of a row of epithelial cells arranged at right angles to the basilar membrane, and not differentiated into hair, pillar, and other supporting cells. There was marked malformation of Corti's organ at the base and apex in Mayer's case, less marked in the middle coil. Alexander notes that in some parts the stria vascularis is absent, in others strongly developed, and shows many vessels. In Iwanow's case the membrana tectoria was atrophied.

Spiral Ganglion and Cochlear Nerve.-Alexander mentions that in his case the ganglion did not take a spiral course but was situated centrally in the modiolus. He believes that the faulty formation of the septa between the various scalæ is associated with the anomalous position of the spiral ganglion. In Alt's case the spiral ganglion was atrophied and connective tissue increased in the spiral canal. The fine branches of the cochlear nerve were reduced. Alexander points out that the condition of the cochlear nerve coincides with that in the lowest inammals-duckmole and echidna. The stem of the eighth nerve is as a rule much less atrophic than the peripheral branches. The central course of the eighth nerve was apparently normal in Alt's case.

Explanation of the Changes found in Mondini's Type.Siebenmann attributes the condition to some abnormality occurring at the fourth month of embryonic life. Alexander points out that the embryonic membranous cochlea is at first covered in by a cartilaginous capsule which gradually assumes the external shape of the fully developed cochlea. A crest which divides off the various coils arises from the inner surface of this cartilaginous capsule and joins a membranous and, later, bony projection from the modiolus. The development of the cochlea takes place from base to apex, so that should the development be arrested at a certain point, these septa may fail to form, with the result that the scala vestibuli of one coil will communicate with the scali tympani of the next higher coil. 


\section{J. S. Fraser}

\section{(3) Congenital Malformation affecting both the (Membranous) Cochlear and Vestibular Apparatus.}

This clinical type of deaf-mutism is frequently associated with retinitis pigmentosa. Cases have been described by Lucæ, Siebenmann and Bing, Bezold, Alexander, Frey and Hammerschlag, Greeff, Oppikofer, Nager, and Kiichi Hane.

Clinical Aspect.-In the type of sporadic congenital deafmutism, to be described later (Scheibe type), in which the cochlea and saccule or the cochlea alone are involved, the vestibular reactions are normal. In the variety under consideration the vestibular reactions are absent (as in most cases of acquired deaf-mutism), or at least greatly diminished. Bezold's two cases showed uncertain gait and great diminution but not apparently complete absence of vestibular irritability. Bezold has examined two deaf patients suffering from retinitis pigmentosa. Of the four ears, one was quite deaf, whereas the other three showed a hearing island towards the middle of the scale. (It is interesting to note that in retinitis pigmentosa there is a contraction of the visual field corresponding to the contraction of the hearing field in these deaf-mute cases. According to Greeff the pathology of retinitis pigmentosa consists in hyaline changes in the vessels, which produce atrophy of the pigmented and sensory epithelium.) Frey and Hammerschlag confirm Bezold's findings in four cases of retinitis pigmentosa. Of these, three at least were mentally feeble. All four failed to react to rotation, while two had deaf-mute imbecile brothers or sisters. With regard to the galvanic reaction, Hammerschlag found that two out of three cases failed to react and that in the third the reaction was much diminished.

Oppikofer's cases were completely deaf from birth. A sister of one of the patients was congenitally deaf. In the second case the father and mother were born deaf. Another case had ten brothers and sisters; of these, seven had died young and two of the seven were deaf from birth. The patient was of poor mental development and walked with a broad base. The vestibular reactions were tested in one of the cases and were found to be absent.

Siebenmann and Bing's case was the fourth of eight children, of whom four were apparently born deaf. A brother of the patient's also had retinitis pigmentosa. The patient was quite 


\section{Pathological Aspects of Deaf-Mutism}

deaf and the galvanic reaction was absent. Nager's case and also Alexander's were imbecile.

\section{Pathology :-}

Middle ears normal.

Vestibular Apparatus.-Siebenmann and Bing found,the maculæ and cristæ degenerated but the vestibular nerve and ganglion normal. Bing found no abnormalities in the central course of the vestibular nerve. In one of Oppikofer's cases the sacculus was dilated on the right side and collapsed on the left. In the other the right sacculus was normal. There was marked atrophy of the vestibular nerve and ganglion in both of Oppikofer's cases. The nerve endings were also atrophied. Nager found the vestibular nerve markedly atrophied and the aqueduct of the vestibule dilated. Hane noted slight atrophy of the cristre of the canals. The epithelial cells of the utricle were irregular and the hair cells absent or at least not recognisable. The vestibular nerve was atrophied.

Cochlear Duct.-This was dilated in both of Oppikofer's cases. Nager found the membranous cochlea dilated or collapsed and the sensory epithelium absent or badly developed. The cochlear duct was collapsed in Hane's case. The spiral prominence was absent in one of Oppikofer's cases, but in Hane's case it showed the form of a tumour. The membrana tectoria was shrunken in Hane's case. The stria vascularis was absent in both of Oppikofer's cases, hypoplasic and in parts absent in Siebenmann and Bing's case, and also in Hane's.

Cochlear Nerve and Ganglion.-The spiral ganglion was markedly atrophied in both of Oppikofer's cases and in Hane's case. Siebenmann and Bing, Nager and also Hane found that the stem of the cochlear nerve was markedly atrophied. The vascularity of the nerve endings in the cochlea and vestibule was poor. (This corresponds to the pathological changes in retinitis pigmentosa.)

Brain.-Bing found no meningitic changes, but noted sclerotic patches in the basilar artery and in the circle of Willis. The first two temporal convolutions, especially on the left side, were very small, and microscopic examination revealed senile endarteritis. The patient, however, was aged 79! Bing noted reduction in the layer of smaller pyramidal cells and marked alterations in the cochlear nuclei. He thought that the changes in the cortical hearing centre were secondary and due to inactivity. Lucæ found the striæ acousticæ atrophic in his case. 


\section{J. S. Fraser}

Remarks.-Little or no explanation has been given of the changes observed in this type of deaf-mutism. The outstanding features are, firstly, the alterations in the blood-vessels noted by some observers; secondly, the hypoplasia of the sensory epithelium in both parts of the membranous labyrinth; thirdly, the atrophy of the cochlear and vestibular ganglia ; and, fourthly, the brain changes observed by Bing. According to Nager's view, Bing's observations are of great importance.

\section{(4) Sacculo-Cochlear Degeneration. (Scheibe's Type.)}

This type of sporadic congenital deafness was first described in I89I by Scheibe, who regarded it as a developmental anomaly. Further cases have been described by Alexander, Alt, Eschweiler, Goerke, Gray, Habermann, Katz, Lindt, Oppikofer, Panse, Quix, Schwabach, Siebenmann, and Watsuji. (The case already described in this paper belongs to the Scheibe type.)

Clinical Aspect.-Alexander estimates that about 70 per cent. of cases of congenital deaf-mutism belong to the "sacculocochlear" type, in which the utricle and canals (pars superior) are intact. Hearing remnants are usually present in these cases. The vestibular apparatus reacts normally to rotation and caloric tests. To illustrate the doubtful value of the histories obtained in cases of deaf-mutism, it is interesting to note that Scheibe's second case was stated to have become deaf as a result of fits during infancy, but the author holds that the child was really deaf from birth. Habermann's case was said to have become deaf at the age of 5 years, owing to a fall on the head, but Habermann does not believe this. Goerke's patient was born deaf. He married a normal hearing woman and they had five children, of whom the youngest was deaf-mute. Panse's patient and his brother were deaf from youth but three sisters heard well. In Oppikofer's case the parents of the patient heard well. They had seven sons and one daughter, and of these, three, including the patient, were deaf from birth. Oppikofer's patient, who was stone-deaf, married a deaf-mute woman whose brother was also a deaf-mute. The marriage produced one daughter, who was deaf, but had a normal vestibular apparatus.

\section{Pathology :-}

Middle Ear.-In his original case Scheibe found adhesions in the tympanic cavity, and, in both of his cases, described atrophy 


\section{Pathological Aspects of Deaf-Mutism}

of the tensor tympani. In Panse's case the posterior limb of the stapes was ankylosed to the window niche. Lindt's patient had suffered from otorrhøa. In one of Oppikofer's two cases there were traces of former suppurative otitis media. Habermann found the drumhead adherent to the promontory, which showed hyperostosis. The footplate of the stapes was ankylosed. As a rule, however, no changes are found in the middle ear. If present, these are merely accidental.

Bony Labyrinth.-This is usually normal, but in Lindt's case there was on one side an otosclerotic focus, though the stapes was not affected. Lindt holds that this focus was not congenital and that it had nothing to do with the patient's deaf-mutism. In Habermann's case the internal meatus was narrow. Gray has investigated four cases by his own method and found that the hollow spaces of the bony labyrinth were larger than normal.

Utricle and Canals. - The neuro-epithelium of the utricle and cristæ of the canals are normal in almost all cases, but in one of Scheibe's cases the nerve to the ampulla of the posterior canal was atrophied and colloid bodies were present in the ampulla.

Saculus. - In Scheibe's original case there were no hair cells evident in the sacculus: the otolith membrane was surrounded by a layer of cells-a condition similar to that around the membrana tectoria in the cochlea in many cases. In Lindt's case the sacculus was almost completely collapsed and the neuro-epithelium absent for the most part. In Goerke's two cases the sacculus was collapsed but epithelial cells were present in parts. In Quix's case the right sacculus was almost obliterated but the left one was dilated. In Oppikofer's case the sacculus was collapsed. The ductus reuniens was obliterated in many cases.

Cochlear Canal.-This may be (I) collapsed in its entirety, or (2) dilated ; (3) it may be dilated at one part and collapsed at another. If the canal is dilated, Reissner's membrane usually takes a vertical course upwards from the beginning of the limbus. The dilatation of the cochlear duct may be so great that the scala vestibuli is obliterated. If the canal is collapsed Reissner's membrane is usually adherent to the remains of Corti's organ or to the basilar membrane (Schwabach). In Oppikofer's case the cochlear canal was dilated on one side and collapsed on the other (as in the present case).

Corti's Organ.-Corti's organ itself may be absent in parts (Quix) or unrecognisable (Panse). In less severe degrees of the 


\section{J. S. Fraser}

affection it may be replaced by cubical or rounded cells (Goerke) or merely "lower than normal," with only the remains of pillar cells (Oppikofer). In Scheibe's second case Corti's organ was almost normal in the upper coils. In numerous cases hyaline bodies are present in the cochlear canal, and in some there is a large amount of pigment present, as in Habermann's case.

The membrana tectoria is usually covered with epithelium and tucked into the internal spiral sulcus, or backwards on to Hushke's tooth. In other cases the membrana tectoria is attached across the scala media to the stria vascularis and covered on both surfaces with a layer of epithelium. In Oppikofer's case the membrana tectoria had, in parts, its normal position.

The stria vascularis may be absent (Habermann and Lindt), or replaced by flat epithelium (Scheibe, Eschweiler and Quix), or by hyaline masses. (Siebenmann calls these masses "colloid," Alexander "mucoid," while Lindt regards them as degenerative products of the epithelium.) The stria formed a polypoid projection into the scala media in at least two of Gray's four cases. The stria was absent or poorly developed in the basal part, normal in the middle portion, and markedly folded in the upper part in Oppikofer's case. The spiral prominence was normal in Scheibe's first case, small in Lindt's, and absent in Habermann's case. The spiral ligament showed dropsical degeneration in Panse's case.

The spiral ganglion usually shows atrophy, especially in the basal part. In Habermann's case only a few ganglion cells were left, along with connective tissue in the spiral canal. In Panse's first case the spiral ganglion was well formed on the right side but atrophied on the left. The ganglion was atrophied in Schwabach's and Oppikofer's cases, reduced in Quix's and also in Goerke's cases, and markedly degenerated in Gray's cases.

The Fine Branches of the Cochlear Nerve were atrophied in Habermann's, Oppikofer's, and Lindt's cases, and absent in Goerke's and in Panse's second case.

Eighth Nerve.-The stem of the cochlear nerve was atrophied on both sides in Scheibe's first case. In his second the eighth nerve appeared to be normal in size, but microscopically the cochlear branch showed atrophy. In Lindt's case the branch to the sacculus was very thin, and in Goerke's case this branch and also that to the posterior canal were 


\section{Pathological Aspects of Deaf-Mutism}

considerably reduced: the stem of the cochlear nerve was degenerated. In two of Gray's cases the cochlear portion showed very few fibres.

Brain.-Numerous cysts were present in the brain in Scheibe's first case, and in the second there was cloudiness of the pia arachnoid. In Panse's second case the striæ accousticæ were not to be seen.

Cases in which the changes are confined to the Membranous Cochlea and Nerve have been described by Katz, Oppikofer, Denker, and Quix. The middle ear and tympanic muscles, the labyrinth capsule, the sacculus and the pars superior of the membranous labyrinth are healthy. The normal condition of the saccule in these cases has been attributed to closure of the ductus reuniens and consequent limitation of the malformation of the membranous cochlea. Otherwise the changes in the scala media are much the same as those described above.

Explanation of the Changes.-Various theories have been advanced to account for the abnormalities observed. The writer has attempted to group these theories under four headings.

(I) Faulty Development.-Oppikofer suggests that the otic vesicle may have been abnormally large, while the cartilaginous cochlea, which develops later, was of normal size. This explanation may account for the fold formation in the membranous cochlea. As an alternative, he suggests that the fold formation may have been due to adhesion of the walls of the cochlear canal, and cites as an analogy the formation of the membranous semicircular canals, which are originally hollow out-growths from the otic vesicle. The central portions of these out-growths become adherent and are absorbed, while only the peripheral part remains to form the canals. If the developmental disturbance occurs in the first two months of foetal life the membrana tectoria is not formed at all or lies as a rudiment in the internal spiral sulcus. In such cases the fine nerve branches and the spiral ganglion remain markedly undeveloped though a few fibres and ganglion cells are always found. If the developmental disturbance occurs later, the membrana tectoria may be properly formed and the ganglion and nerves well developed. Siebenmann has observed healthy nerve bundles, which can be traced to an almost completely degenerated Corti's organ. Habermann has examined anencephalous foetuses and has shown that Corti's organ may attain its full development even in the presence of severe disturbance of the 


\section{J. S. Fraser}

spiral ganglion. For this reason hypoplasia of the ganglion alone cannot be regarded as the cause of the changes in the sensory epithelium. (Oppikofer states that microscopical examination does not explain the slight remains of hearing in his case. He remarks that Siebenmann has demonstrated the ear of a deaf-mute who could hear all vowels and some consonants though Corti's organ was nowhere normal. According to Alexander, in about one-third of the cases circumscribed areas of Corti's organ and the nerve ganglia are functionally efficient, so that there are some remains of hearing.)

(2) Hereditary Weakness of the Ear.-Manasse and also Siebenmann have called attention to the similarity of the changes found in congenital deafness to those seen in chronic progressive labyrinthine deafness. There are, however, some differences, e.g., degeneration of the macula of the saccule and bridge formation between the membrana tectoria and the stria vascularis have been observed in "congenital" but not in "progressive labyrinthine" deafness. Manasse refers especially to cases in which the epithelial metaplasia is confined to the basilar membrane. He believes that the atrophic degenerative process may occur in intra-uterine life, or may at least begin then and continue after birth. Politzer was the first to describe progressive labyrinthine deafness coming on in youth and resulting in marked diminution of hearing or even complete deafness. Politzer thought that the condition was due to an idiopathic atrophy of the acoustic nerve, but Alexander believes that some of the cases at any rate are closely allied to congenital labyrinthine deafness. Spira has called attention to the occurrence of ear disease-otitis media or nerve deafness -in certain families. As a rule the same part of the ear is affected both in parents and children; but in some cases the parents suffered from an inner ear affection, while the children had otitis media. Spira regards these conditions as due to an inherited local lack of resistance. Stein points out that this may be due to two factors-(I) faulty germinal plasma (heredity); (2) faulty intra- and extra-uterine conditions (environment). Gowers in 1902, and Edinger in 1904, called attention to the condition of "abiotrophy," in which there is a want of nervous energy to bear the strain of normal or excessive functional activity. Such conditions as progressive muscular atrophy, primary optic atrophy, and progressive nerve deafness belong to this category. 


\section{Pathological Aspects of Deaf-Mutism}

(3) Increased Pressure in Perilymphatic or Endolymphatic Spaces.-Gray holds that the increase in the size of the hollow spaces of the bony labyrinth may be due to increased intralabyrinthine pressure during fœtal or early post-fœtal life. He thinks that there was increased pressure in the perilymphatic space transmitted from the cranial cavity through the aqueduct of the cochlea, and that this might account for the depressed condition of Reissner's membrane. Dilatation of the cochlear canal, on the other hand, may be due to increased secretion of endolymph from the enlarged stria vascularis. Quix believes that the explanation of the deafmutism is to be found in the stria vascularis, which is a secretory organ, and regulates the supply of endolymph. Habermann explains the polypoid condition of the stria as possibly due to a pull on it by Reissner's membrane which, in his case, was adherent to the stria. Oppikofer believes that the bridge of tissue connecting the membrana tectoria to the region of the stria is really the epithelium of the stria which had been separated from its connective tissue base. Oppikofer appears to suggest that there is a layer of epithelial cells which covers the membrana tectoria, Hushke's tooth and Corti's organ. These epithelial cells should normally disappear, while in deaf-mutism they remain. Gray holds that the condition of the stria in two of his cases indicates a process of repair occurring during foetal life. Pritchard considers that the hypertrophied condition of the stria vascularis resembles very closely the tegmentum vasculosum in the cochlea of birds.

(4) Inflammatory Changes: Meningitis._-Siebenmann, Nager, and Oppikofer believe that the conditions present are due to an intra-uterine inflammatory process. It is common knowledge that meningitis is very frequent during the first year of life. Preysing has recorded two cases of otitis interna in sucklings. One was a complication of purulent meningitis and the other of enteritis and broncho-pneumonia. Both children, however, at the time of death were several days old. Siebenmann mentions the possibility of placental infection as the cause of meningitis in the foetus, when the mother is suffering from smallpox and other infectious diseases. Ballantyne records a case observed by Gradwohl of St Louis. The patient was a woman, aged $3 \mathbf{I}$, seven months pregnant, who suffered from pain in the left ear rapidly followed by coma. Well-marked signs of meningitis were present. The patient died undelivered. 


\section{J. S. Fraser}

Autopsy revealed acute nephritis and purulent basal meningitis. The foetus also showed sero-purulent meningitis. Bacteriological examination of the cerebro-spinal fluid of both mother and foetus revealed the diplococcus intra-cellularis, and the same organism was separated in pure culture from the left ear of the mother. So far, however, there is only the case of Haike which goes to prove the existence of an intra-uterine meningitic labyrinthitis. Great variations have been noticed with regard to the pigmentation of the labyrinth in cases of congenital deafness. In some there appears to be an excessive amount of pigmentation present, while in others the labyrinth pigment is absent. Habermann suggests that the pigmentation of Corti's organ in his case may have been due to an old hæmorrhage. Indeed Habermann thinks the whole condition may have been caused by an inflammatory affection in embryonic life. Herzog has produced labyrinthitis experimentally and found changes in the membranous labyrinth similar to those seen in congenital deaf-mutes. He therefore suggests that these latter may also have been due to inflammation.

\section{Congenital Deafness and Otosclerosis.}

In the foregoing analysis of the various types or grades of developmental or congenital deafness (endemic and sporadic) it has been stated that cases have been examined by Habermann, Schwabach, Panse, Denker, Alexander, Lindt, and Nager, in which a focus of otosclerosis was found in the labyrinth capsule. The connection, if any, between the two conditions is by no means clear. Politzer reports a case in which both window niches were narrowed by hyperostoses. No trace of the stapes was present. Otosclerotic foci were present not only in the neighbourhood of the oval window but also in the region of the canals. The spiral ganglion cells were reduced. Corti's organ was wellformed only in the apical coil. Alexander believes that the presence of an area of otosclerosis in the labyrinth capsule in certain cases of deaf-mutism shows that there is a steppingstone between congenital deafness and the various forms of congenital hardness of hearing. He believes that there is no doubt that the first rudiments of otosclerosis are often of congenital origin and that the ankylosis of the stapes and atrophy of the sensory epithelium are secondary. These congenital foci may exist without giving rise to symptoms until the age of 


\section{Pathological Aspects of Deaf-Mutism}

puberty. Koerner believes that otosclerosis is due to certain determinants in the germinal cells of the parents, but is influenced by puberty, parturition, the climacteric period, and also by diseases of the middle ear. He explains cases of otosclerosis with no apparent heredity by supposing that the disease has skipped some generations. Hagener believes that the primary condition in otosclerosis is a change in the eighth nerve, and, in support of this, points to cases in which tinnitus is the first symptom of the disease. Manasse has shown that the nerve changes are the same in advanced otosclerosis and in pure nerve deafness. Further, we know that there are cases of atypical otosclerosis in which functional examination apparently shows pure deafness, and yet, on microscopic examination, a typical focus is found in the labyrinth capsule. Such cases have been recorded by Alexander, Kalenda, and Stern. Manasse finds that in otosclerosis there is little or no connection between the changes in the labyrinth capsule and the results of clinical examination. Even with a small bony focus we may have the clinical signs of otosclerosis, and, on microscopic examination, the well-marked picture of nerve deafness. Indeed in one case there was in the better hearing ear a focus of otosclerosis, while on the other side the labyrinth capsule was normal. Goerke apparently believes that the focus of pathological bone is only incidental and not of great importance. Nager, however, holds that if the otosclerotic focus adjoins the stapedio-vestibular ligament, we have the well-known Bezold's triad of signs.

Stein is of opinion that in otosclerotics there are always other diseases of degenerative origin. Hammerschlag notes that the bony changes characteristic of otosclerosis have been found in many cases of congenital deafness-not only in the hereditary degenerative (sporadic) type but also in endemic cases. He reminds us that there are families in which cases both of hereditary deafness and otosclerosis are to be found. These facts suggest that hereditary deafness and otosclerosis are to be regarded as different forms of one and the same pathological process.

Edinger has suggested that hereditary deafness appearing in middle age belongs to the group of wasting diseases, in which the normal demands of the organ cannot be replaced. Progressive nerve deafness is obviously to be included in this group and Goerke wishes to put otosclerosis into the same category.

vOL. XXXVII. NO. I. 


\section{J. S. Fraser}

\section{Deaf-mutism associated with Changes in the Brain.}

Castex has stated that in his experience deaf-mutism is usually due to changes in the cortical hearing area and much less often to changes in the ear. He believes that the cortical changes are due to meningitis which is sometimes intra-uterine. Brock states that Oppikofer, Schlittler, and Nager have examined the temporal bones of Endemic deaf-mutes (already reported in this paper) but have been unable to find pathological changes sufficient to account for the deafness observed during life. Brock therefore comes to the conclusion that we must give up the view that in all cases of deaf-mutism the explanation is to be found in malformation or disease of the ear. In his own case Brock noted atrophy of Corti's organ, of the fine nerve fibres going to it, and also of the ganglion cells supplying the basal part. Further, there was a collection of serum in the tympanic cavity, with swelling of the mucosa and fixation of the stapes to the promontory wall. These changes, however, do not, in Brock's opinion, account for the deafness which may be explained by alterations in the sensory hair cells too fine to be recognised by the microscope, or concealed by cadaveric changes. Alternatively Brock suggests that the lesion is not in the peripheral organ but is of central origin.

The question of deafness due to brain lesions is a very difficult one. Microscopic examination of the hearing tracts and centres is a long and tedious process and requires great experience for the proper interpretation of the appearances presented by the different layers of the cortical hearing centre. Probably few, if any, otologists possess this knowledge, and it is therefore necessary for the otologist, who examines the labyrinth, to work in conjunction with a neuro-histologist capable of interpreting the appearances in the brain.

(To be continued.) 